\title{
Comparison of maternity care quality in teaching and non-teaching hospitals in Khorram Abad, Islamic Republic of Iran
}

S.M. Moosavisadat, ${ }^{1}$ M. Lamyian, ${ }^{1}$ S. Parsai ${ }^{2}$ and E. Hajizadeh ${ }^{3}$

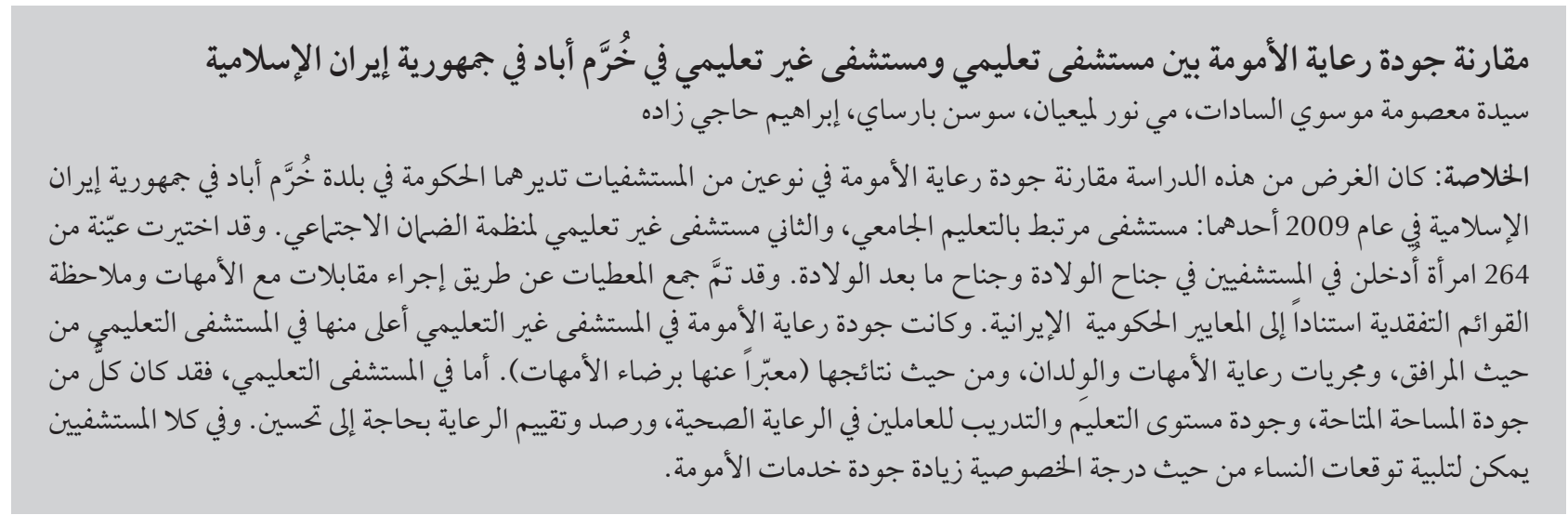

ABSTRACT The objective of this study was to compare the quality of maternity care in 2 types of government-run hospital in the town of Khorram Abad, Islamic Republic of Iran in 2009: a university-linked teaching and a social security organization non-teaching hospital. A sample of 264 women hospitalized in the delivery and postpartum wards was selected. Data collection was done using interviews with mothers and observation checklists based on Iranian government criteria. The quality of maternity care in the non-teaching hospital was higher than the teaching hospital in terms of facilities, processes of maternal and newborn care and outcomes (mother's satisfaction). In the teaching hospital, the quality of the physical space, the educational level and training of health care personnel and monitoring and evaluation of care quality needed improvement. In both hospitals, meeting women's expectations about the degree of privacy could lead to an increase in the quality of maternity services.

\section{Comparaison de la qualité des soins maternels dans un hôpital universitaire et un hôpital non universitaire de la ville de Khorramābād (République islamique d'Iran)}

RÉSUMÉ L'objectif de la présente étude était de comparer la qualité des soins maternels dans deux types d'établissements de soins gérés par le secteur public dans la ville de Khorramābād (République islamique d'Iran) en 2009 : un centre hospitalier universitaire et un hôpital non universitaire affilié à la sécurité sociale. Un échantillon de 264 femmes hospitalisées dans les salles d'accouchement puis dans les services de soins postnatals a été sélectionné. Les données ont été collectées au moyen d'entretiens avec les mères et de grilles d'observation fondées sur les critères du gouvernement iranien. Comparée aux soins maternels prodigués au sein de l'hôpital universitaire, la qualité des soins était supérieure dans l'hôpital non universitaire en termes de locaux, de protocoles de soins à la mère et au nouveau-né et de résultats (satisfaction de la mère). Au sein de I'hôpital universitaire, les caractéristiques des salles, le niveau d'études et de formation du personnel soignant, le suivi et l'évaluation de la qualité des soins devaient être améliorés. Dans les deux hôpitaux, la réalisation des attentes des mères concernant le degré d'intimité pourrait entraîner une augmentation de la qualité des services de soins maternels. 


\section{Introduction}

Worldwide an estimated 515000 women die of complications of pregnancy and childbirth every year, a rate of over 1400 maternal deaths each day [1]. At least 7 million women who survive childbirth suffer serious health problems, and a further 50 million women suffer adverse health consequences after childbirth. The overwhelming majority of these deaths and complications occur in developing countries [1]. Maternal mortality is the main factor that substantially lowers the life expectancy of women [2] and it is a basic human right that pregnancy be made safe for all women [3].

Improving the quality at maternity care services is an effective strategy to reduce maternal mortality [4]. The World Health Organization (WHO) emphasizes the importance of evaluating the structure, process and outcome of health services to improve the quality of care [5]. Structure refers to the overall ability of a midwifery service to provide care and includes such elements as office space, equipment, staff and documentation. Process refers to the way in which care is provided. Outcome indicators examine the results of care in terms of patient satisfaction, clinical outcomes, appropriate use of technology and resources and access to care [6,7]. Quality improvement involves using the data to modify the process of providing care in order to improve the outcomes.

Many studies in developed and developing countries have assessed the quality of maternity care [8-15]. Despite the utmost importance of maternity care in reducing maternal mortality, there have been few published studies about the quality of these services in the Islamic Republic of Iran. The quality of care in different types of hospital is a matter of discussion. The present study in the town of Khorram Abad, the capital city of Lorestan province, therefore aimed to compare the structure, process and outcome of maternity care in 2 types of government-run hospital: a teaching (university) hospital and a non-teaching (social security organization) hospital. The quality standards used were based on those of the Iranian Ministry of Health and Medical Education (MOHME).

\section{Methods}

\section{Sample}

This was a descriptive-analytical study using multistage sampling and was carried out over a 3-month period in 2009 (March to May). In the first stage, hospitals in Khorram Abad were selected from 2 categories of government-run hospital: teaching hospitals (under the supervision of Lorestan University of Medical Sciences) and non-teaching hospitals (under the supervision of the social securityorganization of Lorestan). In the second stage, the only teaching hospital with a maternity ward (Asalian hospital) and the only non-teaching hospital with a maternity ward (Khorram Abad social security hospital) were selected.

In each hospital 2 samples of 132 women were randomly selected: 66 from the delivery ward (where women stay from the beginning of regular uterine contractions until complete dilatation of the cervix) and 66 from the postpartum ward (where mothers are transferred an hour after childbirth until discharge). The women were selected randomly from normal women (women with no known medical or surgical history) who had been hospitalized for at least 6 hours in the delivery ward and from normal women who had stayed at least 6 hours after childbirth in the postpartum ward.

\section{Data collection}

The tool used to assess the quality of processes (e.g. clinical examinations, fetal heart monitoring, training given to mothers) and outcome (mother's satisfaction) was part of a package prepared by the MOHME in 2003 to assess safe motherhood programmes and future needs in the Islamic Republic of Iran [16]. The original questionnaire was separated into 2 questionnaires, 1 for the delivery ward and 1 for the postpartum ward. The questionnaire was used to interview the women about the care they received and their satisfaction with the care. The questionnaire had been previously tested in a pilot study and subsequently modified in 2004 when it was retested and finalized after assessment by an internal review board, an external review board, pilot testing and assessment by an expert panel. According to the author of the standards, Cronbach alpha was 0.81 for the questions about the care process and 0.55 for the satisfaction questions (Cronbach alpha $>0.45$ was defined as acceptable).

To assess the structure of the wards (physical space and equipment), 2 observation checklists, 1 for the delivery ward [15] and 1 for the postpartum ward [13], were completed by the researcher. Data about personnel, such as education level, were obtained from the Information and Statistics section of the maternity ward.

\section{Ethical issues}

This study was approved by the university research ethics committee. The women were informed that all data collected would remain confidential and anonymous. Interviews were conducted only after explaining the objectives of study and obtaining the mothers' consent. The interviewer had rigorous training about the questionnaire, interviewing skills and research ethics.

\section{Data analysis}

For each criterion of the quality of processes and satisfaction with care, the number ofpositiveanswerswassummed ("don't know" answers were considered as missing data) and a percentage was calculated for the sample of women. For the quality of structure, each item 
was scored 1 (present) or 0 (absent), then the percentage was calculated for each field separately (physical space and equipment). The percentages were averaged to give the overall percentage in each field (structure, process and outcome). Percentage scores, both overall and on individualitems, were compared against the MOHME standards which defined scores $<60 \%$ as unfavourable quality, $60 \%-80 \%$ as acceptable quality and $>80 \%$ as excellent quality [17].

The data were analysed using descriptive and analytical statistics including Kolmogorov-Smirnov, independent t-test, Mann-Whitney, chisquared and Fisher exact test in SPSS, version 17 software.

\section{Results}

\section{Delivery ward}

Study samples: general characteristics

For the delivery ward samples there were no significant differences between the women in the teaching and nonteaching hospitals in terms of age [mean age 25.8 (SD 7.0) and 26.8 (SD 5.1) years respectively] $(t=0.94, P=0.34)$, occupation ( $98.5 \%$ and $89.4 \%$ respectively were housewives $)\left(\chi^{2}=4.50\right.$, Fisher exact $P=0.09)$ or number of pregnancies (53.0\% and 54.5\% respectively were primigravidas $)\left(\chi^{2}=3.78, P=\right.$ $0.15)$. However, women in the teaching hospital had a significantly lower level of education (15.2\% and $3.0 \%$ respectively were illiterate, $25.8 \%$ and $15.1 \%$ had $1-5$ years of schooling, $30.3 \%$ and $7.6 \%$ had 6-8 years of schooling, $9.1 \%$ and $9.1 \%$ had 9-11 years of schooling, $16.7 \%$ and $47.0 \%$ had diploma and $3.0 \%$ and $18.2 \%$ had academic education) $\left(\chi^{2}=32.81, P\right.$ $<0.001$ ).

\section{Structure of delivery care}

The quality of physical space in the delivery ward of the teaching hospital was found to be unfavourable (41.6\% compatibility with the standard) while in the non-teaching hospital it was excellent (91.6\% compatibility) and this difference was significant $\left(\chi^{2}=56.19\right.$, $P<0.001)$. The quality of necessary ward equipment in both types of hospital was excellent (100.0\% and 97.2\% compatibility respectively) $\left(\chi^{2}=2.83, P\right.$ $=0.09$ ). The overall structure quality of the delivery ward was acceptable in the teaching hospital ( $70.8 \%$ compatibility) and excellent in the non-teaching hospital ( $94.4 \%$ compatibility), a significant difference $\left(\chi^{2}=19.37, P<0.001\right)$.

The ratio of the number of personnel in the maternity ward to the average number of vaginal deliveries in a month was $1: 11$ and $1: 15$ in the teaching and non-teaching hospitals respectively. The educational level of the care personnel was significantly lower in teaching than non-teaching hospitals; $29.1 \%$ in the teaching hospital had only an associate level of education and $70.8 \%$ a bachelor's degree while in the non-teaching hospital 93.3\% had a bachelor's degree and $6.6 \%$ a master's degree $\left(\chi^{2}=6.59\right.$, Fisher exact $P=0.01$ ).

\section{Process of delivery care}

In both hospitals the quality of delivery care was unfavourable for the items concerning measuring body temperature and observance of privacy/covering for women in labour, but was excellent for fetal heart sound monitoring and vaginal examination (Table 1). Measurement of blood pressure and body temperature was significantly more often done in the non-teaching than teaching hospitals $(P<0.001)$. Overall, the quality of processes of delivery care in the teaching hospital was unfavorable (50.5\% compatibility with the standard) but was acceptable in the non-teaching hospital ( $70.6 \%$ compatibility), a significant difference between the hospitals $(P<0.001)($ Table 1$)$.

Outcome of delivery care (maternal satisfaction)

Women's satisfaction with the items about observance of privacy/covering during examinations $(P=0.04)$ and hygiene of the service provider environment $(P=0.02)$ were significantly better in non-teaching hospitals. In general, the level of women's satisfaction with delivery care in the teaching and nonteaching hospitals was acceptable in

\begin{tabular}{|c|c|c|c|c|c|c|}
\hline \multirow[t]{2}{*}{ Process item } & \multicolumn{2}{|c|}{$\begin{array}{l}\text { Teaching hospital } \\
\qquad(n=66)\end{array}$} & \multicolumn{2}{|c|}{$\begin{array}{l}\text { Non-teaching hospital } \\
\qquad(n=66)\end{array}$} & \multirow[t]{2}{*}{$x^{2}$-value } & \multirow[t]{2}{*}{$P$-value } \\
\hline & $\begin{array}{c}\text { No. of } \\
\text { positive } \\
\text { answers }\end{array}$ & $\%$ & $\begin{array}{c}\text { No. of } \\
\text { positive } \\
\text { answers }\end{array}$ & $\%$ & & \\
\hline Monitoring of fetal heart sounds & 66 & 100.0 & 66 & 100.0 & - & - \\
\hline Measuring blood pressure & 30 & 48.4 & 64 & 97.0 & 40.72 & $<0.001$ \\
\hline Measuring body temperature & 2 & 3.0 & 37 & 56.1 & 44.58 & $<0.001$ \\
\hline Vaginal examination & 66 & 100.0 & 66 & 100.0 & - & - \\
\hline $\begin{array}{l}\text { Observance of privacy \& covering } \\
\text { during examination }\end{array}$ & 1 & 1.5 & 0 & 0.0 & $1.00^{\mathrm{a}}$ & 1.00 \\
\hline Overall standard & - & 50.5 & - & 70.6 & 8.45 & $<0.001$ \\
\hline
\end{tabular}

a Fisher exact test. 
both hospitals (61.0\% and $73.8 \%$ compatibility with the standard respectively) $(P=0.051)($ Table 2$)$

\section{Postpartum ward}

Study sample general characteristics

The mean age of women in the postpartum ward was similar in the teaching and non-teaching hospitals [25.5 (SD 6.7) and 27.0 (SD 6.0) years respectively] $(t=1.32, P=0.18)$. The proportions who were housewives (98.5\% and $92.4 \%$ respectively) and primigravidas ( $48.5 \%$ and $42.4 \%$ respectively) were not significantly different $\left(\chi^{2}=4.07\right.$, Fisher exact $P=0.11$ and $\chi^{2}=1.49, P$ $=0.47$ respectively). Women in the teaching hospital were significantly less well educated than in the non-teaching hospital (21.2\% and 0\% respectively were illiterate, $31.8 \%$ and $22.7 \%$ had $1-5$ years of schooling, $28.8 \%$ and $19.7 \%$ had 6-8 years of schooling, $4.5 \%$ and $7.6 \%$ had 9-11 years of schooling, $12.1 \%$ and $39.4 \%$ had diploma and $1.5 \%$ and $10.6 \%$ had academic education $)\left(\chi^{2}=33.05\right.$, Fisher exact $P<0.001$ ).

The birth weight of most of the newborns were in the range of 2500-4000 g (93.9\% in the teaching hospital and $92.4 \%$ in the non-teaching hospital) $\left(\chi^{2}\right.$ $=2.98$, Fisher exact $P=0.52$ ).

\section{Structure of postpartum care}

The quality of physical space in the postpartum ward of the teaching hospital was unfavourable (44.4\% compatibility with the standard) while in the non-teaching hospital it was acceptable (66.6\% compatibility), a difference which was significant $\left(\chi^{2}=9.97, P<0.001\right)$. The quality of necessary equipment in the ward was excellent in both hospitals (85.1\% and $92.5 \%$ compatibility in teaching and non-teaching hospitals respectively) $\left(\chi^{2}=2.75, P=0.10\right)$. Although the overall quality of structure in the postpartum ward was acceptable in both hospitals, it was significantly better in the non-teaching hospital (64.7\% and $79.5 \%$ compatibility respectively) $\left(\chi^{2}=5.45, P=0.02\right)$.

In both hospitals the care personnel of the delivery and postpartum wards (vaginal deliveries) were the same. Therefore, we did not analyse the educational status of care personnel in the postpartum ward.

\section{Process of maternal postpartum care}

Table 3 shows the quality of processes of postpartum care. The scores for items about instructing mothers about postnatal danger signs and about family planning were unfavourable in both hospitals. However, for all other items the quality of maternal postpartum care was excellent in the non-teaching hospital and either unfavourable or acceptable in the teaching hospital. These differences were significant for all the indicators: examination of the uterus and uterus massage $(P<0.001)$, checking haemorrhage $(P<0.001)$, measuring blood pressure $(P<0.001)$ and body temperature $(P<0.001)$, questioning about urination $(P<0.001)$, teaching hygiene issues $(P<0.001)$ and teaching about danger signs $(P=0.04)$. The overall level of maternal postpartum care was significantly better in the non-teaching hospitals (44.8\% versus $84.5 \%$ compatibility with the standard) $(P<0.001)$ (Table 3).

\section{Process of newborn care}

Table 4 shows that the items concerning teaching mothers about general care of the newborn and danger signs in newborns and in using vitamin supplements for the newborn scored unfavourably in both hospitals. The items for instructing mothers about breastfeeding and of the umbilicus and arranging the next appointment for the newborn check-up were all rated excellent in the non-teaching hospitals, and were significantly better compared with the teaching hospital (all items $P<0.001)$. Teaching about general aspects of newborn care was done significantly better in the teaching hospital $(P=0.01)$. Overall, the quality of process of newborn care was unfavourable in both the teaching and non-teaching hospitals (39.9\% and 56.3\% compatibility with the standard respectively) $(P=0.02)$.

\section{Outcome of postpartum care (maternal} satisfaction)

Mother's satisfaction with the manners of service providers $(P<0.001)$, privacy/covering during examination $(P<0.01)$ and the hygienic conditions of the service provider environment $(P<0.001)$ was significantly higher in the non-teaching hospital (Table 5).

\begin{tabular}{|c|c|c|c|c|c|c|}
\hline \multirow[t]{2}{*}{ Satisfaction item } & \multicolumn{2}{|c|}{$\begin{array}{l}\text { Teaching hospital } \\
\qquad(n=66)\end{array}$} & \multicolumn{2}{|c|}{$\begin{array}{l}\text { Non-teaching hospital } \\
\qquad(n=66)\end{array}$} & \multirow[t]{2}{*}{$x^{2}$-value } & \multirow[t]{2}{*}{$P$-value } \\
\hline & $\begin{array}{l}\text { No. } \\
\text { satisfied }\end{array}$ & $\%$ & $\begin{array}{l}\text { No. } \\
\text { satisfied }\end{array}$ & $\%$ & & \\
\hline Manner of service providers & 45 & 68.2 & 49 & 74.2 & 0.59 & 0.44 \\
\hline Waiting time for receiving services & 47 & 71.2 & 56 & 84.8 & 3.58 & 0.058 \\
\hline $\begin{array}{l}\text { Observance of privacy \& covering during } \\
\text { examination }\end{array}$ & 19 & 28.8 & 30 & 45.5 & 3.92 & 0.04 \\
\hline Hygienic conditions of the ward & 50 & 75.8 & 59 & 89.4 & 5.28 & 0.02 \\
\hline Overall standard & - & 61.0 & - & 73.8 & 3.72 & 0.051 \\
\hline
\end{tabular}




\begin{tabular}{|c|c|c|c|c|c|c|}
\hline \multirow[t]{2}{*}{ Process item } & \multicolumn{2}{|c|}{$\begin{array}{l}\text { Teaching hospital } \\
\qquad(n=66)\end{array}$} & \multicolumn{2}{|c|}{$\begin{array}{l}\text { Non-teaching hospital } \\
\qquad(n=66)\end{array}$} & \multirow[t]{2}{*}{$\chi^{2}$-value } & \multirow[t]{2}{*}{$P$-value } \\
\hline & $\begin{array}{l}\text { No. of } \\
\text { positive } \\
\text { answers }\end{array}$ & $\%$ & $\begin{array}{l}\text { No. of } \\
\text { positive } \\
\text { answers }\end{array}$ & $\%$ & & \\
\hline $\begin{array}{l}\text { Abdominal examination of uterus \& uterus } \\
\text { massage if needed }\end{array}$ & 51 & 77.3 & 66 & 100.0 & 16.92 & $<0.001$ \\
\hline $\begin{array}{l}\text { Checking presence \& amount of } \\
\text { haemorrhage }\end{array}$ & 48 & 72.7 & 65 & 98.5 & 17.76 & $<0.001$ \\
\hline Measuring blood pressure & 31 & 47.0 & 66 & 100.0 & 47.62 & $<0.001$ \\
\hline Measuring body temperature & 0 & 0.0 & 64 & 97.0 & 124.23 & $<0.001$ \\
\hline Questioning about urination & 27 & 40.9 & 66 & 100.0 & 55.35 & $<0.001$ \\
\hline Training in hazard signs after delivery & 12 & 18.2 & 22 & 33.8 & 4.18 & 0.04 \\
\hline Teaching hygiene issues & 46 & 69.7 & 64 & 97.0 & 17.67 & $<0.001$ \\
\hline Training in family planning & 22 & 33.3 & 33 & 50.0 & 3.77 & 0.052 \\
\hline Overall standard & - & 44.8 & - & 84.5 & 34.48 & $<0.001$ \\
\hline
\end{tabular}

The overall satisfaction with postpartum care was rated acceptable in the teaching hospital (65.5\% compatibility with the standard) and excellent in the non-teaching hospital ( $84.6 \%$ compatibility with the standard $)(P<0.001)$.

\section{Time of initiation of breastfeeding}

There was no significant different between the hospitals in the time of initiation of breastfeeding; $59.1 \%$ and $57.6 \%$ of the women in the teaching and non-teaching hospitals respectively began breastfeeding within half an hour after giving birth, $22.7 \%$ and $25.8 \%$ between $0.5-1$ hours and $12.1 \%$ and $15.2 \%>1$ hour after giving birth (6.1\% and $1.5 \%$ of the women did not lactate in the postpartum ward) $(P=0.59)($ Table 6).

\section{Discussion}

The demographic characteristics of the samples of women were similar in the 2 hospitals, except for education level which was significantly lower in the teaching hospital. This can be explained by the different areas of residence and types of insurance of the people going to each hospital. Most people going to the teaching hospital were residents of villages and had rural insurance which has been in operation since 2005 and allows patients to be referred within the health services. Most of those going to the non-teaching hospital were urban residents with social security organization insurance.

\begin{tabular}{|c|c|c|c|c|c|c|}
\hline \multirow[t]{2}{*}{ Process item } & \multicolumn{2}{|c|}{$\begin{array}{l}\text { Teaching hospial } \\
\qquad(n=66)\end{array}$} & \multicolumn{2}{|c|}{$\begin{array}{l}\text { Non-teaching hospital } \\
\qquad(n=66)\end{array}$} & \multirow[t]{2}{*}{$x^{2}$-value } & \multirow[t]{2}{*}{$P$-value } \\
\hline & $\begin{array}{c}\text { No. of } \\
\text { positive } \\
\text { answers }\end{array}$ & $\%$ & $\begin{array}{c}\text { No. of } \\
\text { positive } \\
\text { answers }\end{array}$ & $\%$ & & \\
\hline $\begin{array}{l}\text { Training mother about newborn danger } \\
\text { signs }\end{array}$ & 7 & 10.6 & 13 & 19.7 & 2.12 & 0.14 \\
\hline $\begin{array}{l}\text { Teaching mother about breastfeeding } \\
\text { methods }\end{array}$ & 48 & 73.8 & 66 & 100.0 & 19.83 & $<0.001$ \\
\hline $\begin{array}{l}\text { Instructing mother about vitamin } \\
\text { supplements for the newborn }\end{array}$ & 20 & 30.7 & 19 & 28.8 & 0.06 & 0.80 \\
\hline $\begin{array}{l}\text { Instructing mother about how to take } \\
\text { care of the umbilicus }\end{array}$ & 15 & 22.7 & 58 & 87.9 & 56.66 & $<0.001$ \\
\hline $\begin{array}{l}\text { Teaching mother about general newborn } \\
\text { care }\end{array}$ & 10 & 15.2 & 2 & 3.0 & 5.86 & 0.01 \\
\hline $\begin{array}{l}\text { Arranging next appointment for newborn } \\
\text { check-up }\end{array}$ & 57 & 86.4 & 65 & 98.5 & 6.92 & $<0.001$ \\
\hline Overall standard & - & 39.9 & - & 56.3 & 5.38 & 0.02 \\
\hline
\end{tabular}




\begin{tabular}{|c|c|c|c|c|c|c|}
\hline \multirow[t]{2}{*}{ Satisfaction item } & \multicolumn{2}{|c|}{$\begin{array}{l}\text { Teaching hospital } \\
\qquad(n=66)\end{array}$} & \multicolumn{2}{|c|}{$\begin{array}{c}\text { Non-teaching } \\
\text { hospital }(n=66)\end{array}$} & \multirow[t]{2}{*}{$\chi^{2}$-value } & \multirow[t]{2}{*}{$P$-value } \\
\hline & $\begin{array}{l}\text { No. } \\
\text { satisfied }\end{array}$ & $\%$ & $\begin{array}{c}\text { No. } \\
\text { satisfied }\end{array}$ & $\%$ & & \\
\hline Manner of service providers & 50 & 75.8 & 63 & 95.5 & 10.39 & $<0.001$ \\
\hline $\begin{array}{l}\text { Observance of privacy \& covering during } \\
\text { examination }\end{array}$ & 29 & 43.9 & 42 & 64.6 & 5.64 & 0.01 \\
\hline Hygienic conditions of the ward & 50 & 76.9 & 62 & 93.9 & 7.64 & $<0.001$ \\
\hline Overall standard & & 65.5 & & 84.6 & 9.74 & $<0.001$ \\
\hline
\end{tabular}

Our findings about the structure of care in the delivery and postpartum wards showed that although the availability of necessary equipment was judged to be excellent against the MOHME standard, numerous deficiencies were observed in the teaching hospital concerning physical space (e.g. space, temperature, ventilation, isolated room for infectious delivery). Another study in the Islamic Republic of Iran also showed that shortages in the standards of physical space were greater than the limitations of necessary equipment in the delivery wards of hospitals [15]. Results of a study in India revealed that differences between women's experience of the hospital environment (the bed, sheets, food, toilets and so on) varied significantly between the public and the private sectors. Women's experience of the human and physical resources was uniformly better at private than public facilities [11]. The results of the public and the private sectors in the above study were similar to those of the teaching and non-teaching hospitals in our study.
We found that $50.5 \%$ and $70.6 \%$ of the process of delivery care items were compatible with the standard in the teaching and non-teaching hospitals respectively. In the study in Kordestan, Islamic Republic of Iran midwifery care was $71.4 \%$ compatible with the desired standard in the first stage of labour [15] and this agrees with the findings of our study in the non-teaching hospital. A study in Uganda showed that many midwives provided poor quality delivery care [8] which agrees with our findings for delivery care in the teaching hospital. In our study, the following factors which affect the quality of the process of delivery care needed to be improved: observance of privacy and covering during examination and measuring body temperature in both hospitals and measuring blood pressure in the teaching hospital. Our findings were different from a study in Kordestan in which the unsatisfactory domains were emotional support for the woman and control of uterine contractions [15]. Hulton et al.'s study in India found that $77 \%$ of women had their blood pressure taken and $70 \%$ had the fetal heart rate listened to at private hospitals compared with $61 \%$ and $55 \%$ at public hospitals [11]. In our study the items for control of fetal heart sounds (100\% in both hospitals) and measuring blood pressure $(97.0 \%$ in the non-teaching hospital) were performed better. While these studies were similar to our study in some respects, neither used MOHME standards which may explain the differences.

Our findings suggest that improvements are needed in the quality of care process in the postpartum ward concerning training mothers about hazard signs after delivery, family planning, general newborn care, newborn danger signs and vitamin supplements for the newborn (in both hospitals) and concerning measuring blood pressure and body temperature of the mother, questioning about urination and instructing mothers in how to take care of the umbilicus (in the teaching hospital). Simbar etal. in Kordestan demonstrated that postpartum care was poor for $82 \%$ of women and the quality of care was unfavourable for control of vital signs,

\begin{tabular}{|c|c|c|c|c|c|c|}
\hline \multirow[t]{2}{*}{$\begin{array}{l}\text { Time of initiation of } \\
\text { breastfeeding (hours) }\end{array}$} & \multicolumn{2}{|c|}{$\begin{array}{l}\text { Teaching hospital } \\
\qquad(n=66)\end{array}$} & \multicolumn{2}{|c|}{$\begin{array}{l}\text { Non-teaching hospital } \\
\qquad(n=66)\end{array}$} & \multicolumn{2}{|c|}{$\begin{array}{c}\text { Total } \\
(n=130)\end{array}$} \\
\hline & No. & $\%$ & No. & $\%$ & No. & $\%$ \\
\hline$<0.5$ & 39 & 59.1 & 38 & 57.6 & 77 & 58.3 \\
\hline $0.5-1$ & 15 & 22.7 & 17 & 25.8 & 32 & 24.2 \\
\hline$>1$ & 8 & 12.1 & 10 & 15.2 & 18 & 13.6 \\
\hline Did not lactate & 4 & 6.1 & 1 & 1.5 & 5 & 3.8 \\
\hline
\end{tabular}

$\chi^{2}=2.04, P=0.59$ Fisher exact test . 
training about breastfeeding, advising caution when leaving bed, psychological care, urinary system assessment, training about perineum care, uterus assessment, digestive system assessment, training before discharge, training about care of the infant, perineum assessment and breast examination [13]. Our results agree with the above study in some areas. In another study in Zahedan, Islamic Republic of Iran, postpartum care quality in hospitals was weak in $98.6 \%$ of cases [14].

Our findings showed the mother's satisfaction with delivery care was $61.0 \%$ and $73.8 \%$ in the teaching and nonteaching hospitals respectively. In the study by Simbar et al. the mean satisfaction with delivery care was $81.7 \%$ [15], which is higher than our results. In our study, satisfaction with postpartum care was $65.5 \%$ and $84.6 \%$ in the teaching and non-teaching hospitals respectively. The most unsatisfactory aspect of maternity care was the item "observance of privacy and covering during examination" in both hospitals. The study by Simbar et al. showed that mothers were satisfied with the care provided in all domains in the postpartum ward, and that the main source of dissatisfaction was caused by personnel behaviour towards their visitors in the hospital [13]. In Stahl's study in Germany, overall satisfaction with maternity care in hospitals was high; clinical expertise, emotional support and successful communication were the key indicators for quality in postnatal maternity care as viewed by women [18].

In a study in Karachi, Pakistan patients' level of satisfaction increased from $34.4 \%$ to $82.0 \%$ over a period of 1 year when sharing of results and capacity-building workshops were arranged to sensitize the hospital staff to work towards improving patients' satisfaction [19]. After identifying the main reasons for dissatisfaction in our study, we can resolve the problem by putting screens around beds and sensitizing personnel to observation of privacy and covering of the patients. Having a private and covered environment for examinations is a right for all women.

WHO has recommended 10 steps to successful breast-feeding in which step 4 is "help mothers initiate breastfeeding within a half-hour of birth" [20]. Our findings showed nearly $60 \%$ of the women in the postpartum ward of both hospitals began breastfeeding within half an hour after giving birth.

Every woman has the right to health care during pregnancy and childbirth [21]. Our findings about the number of antenatal routine visits indicated that the majority of all women in the delivery and postpartum wards of both teaching and non-teaching hospitals (81.3\%) had suitable number of antenatal routine visits based on the standard of the Iranian MOHME (at least 7 antenatal visits) [16].

A positive aspect of our study is that it measured the quality of services in different aspects - structure, process and outcome. Nevertheless the study has some limitations. One is concerned with MOHME's quality evaluation tool for the care process, which is based on minimum standards and it would be better in future studies to evaluate care against excellent standards. Another limitation is concerned with the method of collecting quality of care process data by interviews with mothers, since it is possible that women's responses to the interviewer were biased. Thus observations of care provision rather than interviews with clients are suggested for future studies.

\section{Conclusion}

Our results found that the quality of provision of maternity care was higher in the non-teaching hospital compared with the teaching hospital for all the fields of structure, process and outcome. Several reasons can be suggested for this, including the poorer physical space, lower educational level of care personnel and lower educational level of clients in the teaching hospital. Another factor which needs to be investigated is whether assignment of duties to students may be detrimental to good performance in the teaching hospital. In the non-teaching hospital, more attention should be paid to providing training to the mother. Screening beds and sensitizing staff to the need to observe the privacy of women could improve clients' level of satisfaction in both types of hospital. Finally, to improve the quality of maternity services, we recommend gaining a true understanding of the clients' expectations and ensuring that all required resources for realization of standards are available, that staff have adequate education and that processes of monitoring and evaluation are in place.

\section{Acknowledgements}

We would like to acknowledge the support of Tarbiat Modares University. We are also grateful for the help and continuous assistance of the research deputy of the Medical Faculty, the Social Security Organization of Lorestan and Lorestan University of Medical Sciences.

\section{References}

1. Advancing safe motherhood through human rights. Geneva, World Health Organization, 2001: Chapter1 (WHO/RHR/01.5; http://whqlibdoc.who.int/hq/2001/WHO_RHR_01.5.pdf, accessed 3 July 2011).
2. Garg BS, Chhabra S, Zothanzami SM. Safe motherhood: social, economic, and medical determinants of maternal mortality. Women and health learning package. Karachi, Pakistan, The Network: Towards Unity for Health, 2006. 
3. Kwast BE. Quality of care in reproductive health programmes: monitoring and evaluation of quality improvement. Midwifery, 1998, 14:199-206.

4. Macassa G. Maternal mortality and quality of maternity care (implications for Pakistan) [Masters of Health Promotion thesis] Stockholm, Karolinska Institute, 2005.

5. Mother-baby package: Implementing safe motherhood in countries. Geneva, World Health Organization, 1996.

6. Ament L. Quality management activities in the obstetric triage setting. Journal of Nurse-Midwifery, 1999, 44:592-599.

7. Quality management in midwifery care. Position statement American College of Nurse-Midwives [online factsheet] (www. midwife.org/siteFiles/position/Quality_Management_05.pdf, accessed 15 June 2011).

8. Kaye D. Quality of midwifery care in Soroti District, Uganda. East African Medical Journal, 2000, 77:558-61.

9. Mngadi PT et al. Quality of maternity care for adolescent mothers in Mbabane, Swaziland. International Nursing Review, 2002, 49:38-46.

10. Melkamu Y et al. Assessment of quality of post abortion care in government hospitals in Addis Ababa, Ethiopia. Ethiopian Medical Journal, 2005, 43:137-49.

11. Hulton LA et al. Applying a framework for assessing the quality of maternal health services in urban India. Social Science \& Medicine, 2007, 64:2083-2095.

12. Fenwick J et al. Western Australian women's perceptions of the style and quality of midwifery postnatal care in hospital and at home. Women and Birth, 2009, 23:10-21.

13. Simbar $M$ et al. Assessment of quality of care in postpartum wards of Shaheed Beheshti Medical Science university hospitals, 2004. Italian Journal of Public Health, 2005, 2:148.
14. Khazaeian S. Assessment of quality of postpartum care in Zahedan hospitals [Master of Science thesis]. Islamic Republic of Iran, Shaheed Beheshti University of Medical Sciences, 2007.

15. Simbar M et al. Assessment of quality of midwifery care in delivery and delivery wards of selected Kordestan Medical Science University hospitals. International Journal of Health Care Quality Assurance, 2009, 22(3):266-277.

16. Heydarzadeh A, Azemikhah A. [New system of evaluation of reproductive health programs]. Tehran, Ministry of Health and Medical Education of Iran, Deputy of Health, Family and Population Office, 2003 [in Farsi].

17. Azemi-Khah A, Heydarzadeh A. [New system of monitoring of reproductive health services]. Tehran, Ministry of Health and Medical Education of Iran, Deputy of Health, Family and Population Office, 2003 [in Farsi].

18. Stahl K. Wie zufrieden sind Frauen mit ihrer Geburtsklinik [How satisfied are women with maternity care in hospital]? Zeitschrift fur Geburtshilfe und Neonatologie, 2009, 213:7-11.

19. Shaikh BT et al. Using SERVQUAL for assessing and improving patient satisfaction at a rural health facility in Pakistan. Eastern Mediterranean Health Journal, 2008, 14: 447-456.

20. Ten steps to successful breastfeeding. United Nations Children's Fund [online factsheet]. (http://www.unicef.org/newsline/ tenstps.htm, accesses 15 June 2011).

21. Facts for life: safe motherhood. United Nations Children's Fund [onoine factsheet] (http://www.factsforlifeglobal.org/02/7. html, accessed 15 June 2011). 